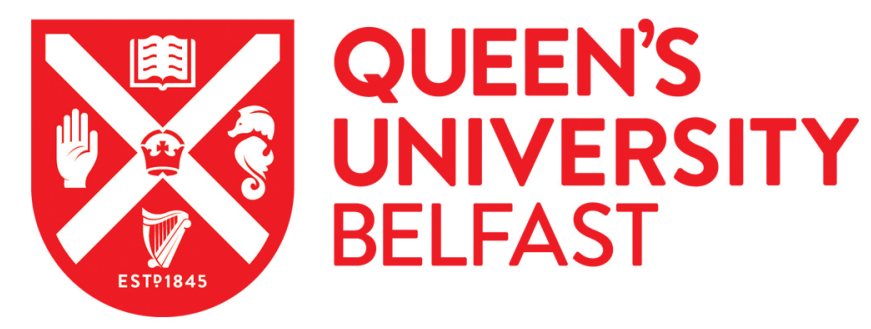

\title{
Scoping systematic review on the extent, nature and quality of evidence underlying ophthalmic and paraophthalmic education
}

Williams, M., Boohan, M., \& Thurston, A. (2017). Scoping systematic review on the extent, nature and quality of evidence underlying ophthalmic and paraophthalmic education. Evidence-based medicine, 22(1), 23-26. https://doi.org/10.1136/ebmed-2016-110542

Published in:

Evidence-based medicine

Document Version:

Peer reviewed version

Queen's University Belfast - Research Portal:

Link to publication record in Queen's University Belfast Research Portal

Publisher rights

Copyright 2017 The Authors

This work is made available online in accordance with the publisher's policies.

\section{General rights}

Copyright for the publications made accessible via the Queen's University Belfast Research Portal is retained by the author(s) and / or other copyright owners and it is a condition of accessing these publications that users recognise and abide by the legal requirements associated with these rights.

Take down policy

The Research Portal is Queen's institutional repository that provides access to Queen's research output. Every effort has been made to ensure that content in the Research Portal does not infringe any person's rights, or applicable UK laws. If you discover content in the Research Portal that you believe breaches copyright or violates any law, please contact openaccess@qub.ac.uk. 
2016-110542-R1

\section{Title page.}

Title:

A scoping systematic review on the extent, nature and quality of evidence underlying ophthalmic and paraophthalmic education.

Corresponding author:

Dr Michael Williams

Centre for Medical Education, Queen's University of Belfast,

Mulhouse Building, Royal Victoria Hospital, Belfast, BT12 6BJ

Tel.: +44 (0)2890632591

Fax: 02890329899

Email: m,williams@qub.ac.uk

Co-authors:

Mairead Boohan, Centre for Medical Education, Queen's University of Belfast, UK

Allen Thurston, Centre for Effective Education, Queen's University of Belfast, UK

Word count: 2609 
2016-110542-R1

Keywords:

Ophthalmology

Medical Education and Training

\section{Contributorship statement.}

MW conceived of the study, conducted the review, wrote the results and discussion and submitted the paper. MB advised on the methods and proof read the script. AT advised on the methods, results and discussion. 
2016-110542-R1

Abstract.

\section{BACKGROUND.}

Effective education of relevant professionals underpins provision of quality eye health care.

\section{OBJECTIVES.}

This scoping systematic review had two aims: firstly to investigate the extent and nature of scholarly output published on ophthalmic and paraophthalmic education, and secondly to focus on the quality of reporting of randomized controlled trials (RCTs) identified.

\section{STUDY SELECTION.}

A search strategy was created and applied to PubMed. Any scholarly publications on any aspect of education of those involved in the care of patients with visual problems as the main theme or context was selected. Predefined data were extracted.

\section{FINDINGS.}

Of 255 studies included, the most common type of scholarly publications were descriptions of an educational innovation, opinion pieces and descriptive studies. RCTs made up 5.5\% of the sample. Most of the 14 RCTs failed to report most of the items recommended in the CONSORT guidelines.

\section{CONCLUSIONS.}

This review highlights the need for investigators, ethical committees and journals to insist on a better quality of RCT conduct than is presently apparent, but also that clinicians should not be blind to the strengths of nonRCT based studies in the field of education. 
2016-110542-R1

\section{INTRODUCTION.}

A comprehensive review of best practices in teaching ophthalmology to medical students argues that research is needed to reinforce the enhancement of medical student ophthalmology education [1]. In order to guide the planning of such research, an evaluation is needed of current published evidence with regard to quality and scope. Most evidence suggests that medical trainees and practitioners believe that their ophthalmic training has not equipped them with confidence. In a survey of Canadian medical students, $47 \%$ of the 208 responders in the clinical phase of their course reported being "not at all" or "a little" confident in using a direct ophthalmoscope [2]. Eight-nine percent of 145 medical interns responded to a survey on their ophthalmology teaching in a study in Nigeria [3]. Gaps in selfreported competence were identified, particularly relating to posterior segment eye disease. GPs in the UK stated they would like more teaching in ophthalmology [4].

Effective education underpins a safe and quality health care service. It has been suggested that many curricula, far from being evidence based, are derived from other factors. For example "editorial rumination" is described as "setting pedagogical direction" [5]. It has been suggested that decisions about teaching are often made on the basis of "prejudices, hunches, opinions and guesses: PHOG" [6]. The lack of an evidence base to experts' opinions does not make them incorrect. At the very least, experts' guidance generates hypotheses and discussion, and at best are to be valued. Approaches to ophthalmic education may reflect local factors such as professional interests, 
2016-110542-R1

educational resources, the style of the educational institution, local population health needs, or tradition and "evangelical partisanship" [7].

However it is argued that "the evidence base is as important in educating new doctors as it is in assessing new chemotherapy" [7]. A recent review states that we should seek or contribute to education evidence that explains why educational strategies work [8]. Randomised controlled trials (RCTs) are held in the highest regard by ophthalmologists as a source of evidence. As in a drug trial, it is advised that an experimental educational method should not be applied to the 'real world', outside the context of an RCT, until its effectiveness is proven [9]. 'Best Evidence in Medical Education' is an international working group set up to systematically answer specific research questions based on the evidence available and highlighting areas of lack of evidence. However a review of educational publications not specific to ophthalmology found only a small proportion were RCTs, and methodological deficiencies were common in the RCTs [10].

The extent, nature and quality of evidence available on which to base teaching of ophthalmology to medical and other professions have not been reported. As the care of patients with eye or visual problems involves teamwork [11], any such study should include the 'paraophthalmic disciplines', i.e. participants were regarded as those professions involved in the care of people with visual or ocular problems as well as ophthalmologists. The aims of the present review were to investigate the extent and nature of scholarly output published on ophthalmic and paraophthalmic education, specifically highlighting what proportion was formed by RCTs, and to focus on the nature and quality of any RCTs identified. Given the broad nature of "scholarly 
2016-110542-R1

output" as an output for this review, it was described as a 'scoping systematic review'.

\section{METHODS.}

This scoping systematic review followed the 'Preferred Reporting Items for Systematic Reviews and Meta-Analyses' (PRISMA) [12] guidelines as closely as possible to guide the conduct and report of this review. It was not registered. Interventions and outcomes were not relevant terms to use, rather any scholarly publications on any aspect of education of those involved in the care of patients with visual or ocular problems as the main theme or context were included. Any type of scholarly output was included, whether experimental or non experimental. An electronic search was performed on PubMed to identify potentially relevant publications using pre-specified criteria. Other databases were not used as a balance was struck between feasibility and comprehensiveness, reflecting the scoping intent behind the review. Papers published in English from 2006 to 2015 were potentially included, as in 2006 the expert consensus derived ICO guidelines on medical student ophthalmic education were published [13], which plausibly could have influenced scholarly activity on the subject. Several stages were followed to identify the sample of publications for analysis, all performed by one author, MW, gathering data on Microsoft Excel. Firstly search terms were established. Appropriate search terms were defined as those that maximized coverage while minimizing excess numbers of returns. Secondly the search terms were applied to PubMed to produce a list of 'possibly eligible' publications. Thirdly, 
2016-110542-R1

publications were selected from this list in two steps. In step one, publications were excluded only if they were obviously ineligible. In step two of publication selection, abstracts and the full text when necessary for clarification were assessed and 'probably eligible' studies were identified. The resulting list was examined and duplicates removed, forming the list for analysis. For each publication, the publication category was recorded, such as RCT, opinion piece, cohort study etc... Then RCTs were examined in more detail to extract pre-defined data: sample characteristics, intervention, outcome measures and results. For RCTs' results, if possible, effect size was calculated using Cohen's d formula: effect size $=($ mean of experimental group - mean of control group) / standard deviation of control group

95\% confidence intervals (Cls) were calculated for the effect size using the formula [14]:

$$
\sigma[d]=\sqrt{\frac{\mathrm{N}_{\mathrm{E}}+\mathrm{N}_{\mathrm{C}}}{\mathrm{N}_{\mathrm{E}} \times \mathrm{N}_{\mathrm{C}}}+\frac{d^{2}}{2\left(\mathrm{~N}_{\mathrm{E}}+\mathrm{N}_{\mathrm{C}}\right)}}
$$

Finally quality of RCT was assessed using a selection of items adapted from the CONSORT guidelines [6]. Adherence with each item was dichotomised into 'yes' or 'no' based on the full text. No assessment of risk of bias across studies was done given the scoping nature of this review. 


\section{RESULTS}

In search strategy one, the following keywords were used, searching title, abstract and keywords of each database or journal: [(ophthalmo*) OR (optomet*) OR (orthopi*) OR (acuity) OR (optic*) OR (retina*) OR (cataract) OR (glaucoma*) OR (cornea*) or (eyelid*)] AND [(education*) or (learn*) OR (teach*) OR (assessment) OR (feedback) OR (profession*) OR (pastoral) OR (curricul*) OR (undergrad*) OR (postgrad) OR (academ*)]. This strategy led to over 68000 papers returned, judged to be an impractical number to examine. Search strategy two (appendix 1) consisted of twelve separate searches, the results of The list of 2188 titles for each set of search terms was read once and 'possibly relevant' titles selected. Those titles not selected on the first run were all reread. If it was not clear whether a title was pertinent or not, it was included. 1794 titles were obviously not relevant and therefore excluded. For example many publications related to patient education. Three hundred and ninety-four titles remained, the abstracts of which were read. If needed for clarification the full text was read. Ninety-seven were ineligible. Two hundred and ninety seven papers remained. The list of 297 papers was examined closely and 51 duplicates were identified: these were removed. The 255 publications remaining were categorized by study type, 9 of which were preplanned but 2 of which, 'conference reports' and 'historical reflections', emerged during the data extraction process. Study types definitions were as follows: a "commentary/editorial" was an opinion piece; a "narrative review" was a review of a topic not using a systematic search, but rather relying on the authors' experience and interpretation; a "systematic review" was a review 
using a pre-planned and rigorously applied search method to identify relevant studies for analysis; a "description of innovation" was a paper reporting an education method, curriculum, technology or any other aspect of education presented as novel; a "conference report" was a paper describing the highlights of a relevant conference; a "cohort survey" was a non controlled prospective study recording data before and after an intervention, either students' opinions, attitudes or clinical skills; a "descriptive study" was a paper reporting a study in which a survey was performed capturing data at one point in time, for example seeking students' opinions on a curriculum or a novel means of delivering content; a "retrospective study" was a paper presenting data obtained by retrospective analysis, e.g. of factors predicting exam results; a "qualitative study" was a paper describing data obtained and analysed in a qualitative way, e.g. through focus groups; a "historical reflection" was a piece reflecting on ophthalmic education in the past, and a "cost analysis" was a paper analyzing the cost of an educational intervention. The number and percentage in each category are shown in the table 1.

Table 1. Number (\%of total sample) of publications in each category.

\begin{tabular}{|l|l|}
\hline Publication category & Number (\% of sample) \\
\hline Description of innovations & $81(31.8)$ \\
\hline Descriptive study & $47(18.4)$ \\
\hline Commentary/editorial & $45(17.6)$ \\
\hline Cohort survey & $35(13.7)$ \\
\hline Narrative reviews & $11(4.3)$ \\
\hline Retrospective study & $9(3.5)$ \\
\hline
\end{tabular}


2016-110542-R1

\begin{tabular}{|l|l|}
\hline Systematic reviews & $4(1.6)$ \\
\hline Qualitative study & $5(1.4)$ \\
\hline Conference report & $2(0.8)$ \\
\hline Historical reflection & $1(0.4)$ \\
\hline Cost-analysis & $1(0.4)$ \\
\hline
\end{tabular}

Of the 14 RCTs (appendix 2), participants were medical students in 9, postgraduate medical trainees in 4 , and both stages in 1 . Age was not given in 10 of the 14 RCTs.. The total sample sizes varied from 15 to 215 (median 37.5). The interventions in the RCTs were based on surgical simulation in 7 , e-learning in 5 and direct ophthalmoscopy in 2 . The outcomes measured were change in attitudes in 1, change in knowledge in 4 and change in skills in 9. The number of RCTs adhering to items from the CONSORT checklist ranged from 0 (in no study report was it stated that the randomization sequence was concealed until assignment occurred) to 1 (1 study gave the approach to analysis) to 14 (all studies gave an estimate of the effect of each intervention group). Three RCTs mentioned power, 2 of these acknowledging that the study may be underpowered. Effect sizes could not be calculated for 9 of the 14 RCTs, as the numbers in each intervention arm were not given in 4 cases, and relevant standard deviations were not stated in 5 . Effect sizes when they could be calculated were: Grodin et al, 0.5, 95\% Cls 0.3; Steedman et al 0.8; 95\% Cls 0.4; Succar et al 1.0, 95\% Cls 0.2; Kong et al 1.0, 95\% Cls 1.0 and Feldman et al $0.4,95 \%$ Cls 0.5 . 
2016-110542-R1

\section{DISCUSSION}

This study is the first of which we are aware to summarise the nature of evidence underlying education of those engaged in the care of patients with visual problems, and highlights interesting issues relating to evidence in medical education, as well as in the specific field. A wide range of scholarly output categories was demonstrated. The most common type of scholarly output described was an innovation (31.8\%), thus disseminating an idea. The next most common types were commentary pieces (17.6\%), often in the form of an editorial, and descriptive studies (18.4\%) capturing data at one point in time with no comparison being made.

RCTs are considered by clinicians as providing almost the highest level of evidence possible, with only meta-analyses of systematic reviews being more valued. Only a small proportion (5.5\%) in this sample reported RCTs. Why is this? The first reason is philosophical. In order to answer pedagogical questions, qualitative methods uncover insights and reactions, rather than restricting possible outcomes to specific items defined by the investigator in an RCT. Indeed on a more fundamental level the "gravitational pull" of paradigms drawn from the physical sciences, based on the 'imperatives of proof and simplicity', may be an inappropriate approach to medical educational research in general [15]. A rich variety of research disciplines should inform medical educational research [16]. It is argued that more is learnt by asking 'what is happening and how does it apply to my context' rather than 'did it work?' A second reason is practical: RCTs may be considered too difficult to conduct reliably in an education setting [17] as there are challenges not present in clinical studies. Titrating and standardizing 
2016-110542-R1

pedagogical interventions is difficult: educational researchers cannot be sure how much therapy 'was received by the student' [18]. Blinding of students or teachers to the intervention may not be possible. In cross over designs it may be difficult to prevent cross-contamination of 'learning' between groups. It may also be difficult to define exactly what aspect of an intervention led to any difference. It is difficult to control for some aspects of the intervention in an educational setting, such as enthusiasm of a teacher. Another potential difficulty is the type of outcome chosen. The adapted Kirkpatrick scale [19] is usually cited as a measure of gradually increasing superiority of outcome in educational studies, that is attitudes, knowledge, skills and finally patient benefit, but equally describes gradually increasing difficulty of capturing the outcome. Medical education is ultimately translational in nature [20]. However demonstrating benefit of an educational intervention to patients may be impossible: reflecting this, it is rarely done. A systematic review of simulation based instruction found only 50 of 985 studies (5\%) presented patientreported outcomes, and even when such reporting occurred, the analysis was fraught with methodological errors [21]. Even if association between an educational intervention and an outcome can be demonstrated by an RCT, causation may be impossible to infer.

Despite these challenges, RCTs may provide valuable information regarding medical education if conducted rigorously. Examination of the RCTs identified in this review revealed weaknesses. For example not giving participants' ages may be important. First year medical students at 22 years of age may have better study skills and a more mature attitude to learning than 18 year old first year medical students and thus in any study, grouping students of these two 
2016-110542-R1

ages into one group may miss a possible influence of age on outcome. Most RCTs in this sample did not adhere to most CONSORT items in their reporting. The importance of CONSORT in clinical practice is that without adequate reporting, it is hard to judge the internal and external validity of an RCT and uncertainty follows about whether to endorse and apply the RCT's findings. However it may not be possible to conduct a CONSORT-compliant trial in medical education. Effect sizes with Cls could not be calculated for most RCTs due to relevant information not being reported. For the study by Succar et al on the impact of a 'Virtual Ophthalmology Clinic' on the knowledge of medical students, the effect size of 1.0 with $\mathrm{Cls}$ of 0.2 indicated an effective intervention [22].

The use of only one database, PubMed, which has as its focus clinical medicine, would be expected to result in many relevant publications relating to non-medical professions not being found. Furthermore having only one author (MW) select studies is a potential source of bias, though study selection criteria and data to be extracted were predefined. It is unclear whether such potential sources of bias would have affected the proportion of RCTs in the sample. For example it is unknown whether databases other than PubMed cover a range of journals that tend to publish a higher proportion of RCTs than non-RCTs.

With regard to ophthalmic and paraophthalmic education, many topics other than those explored by the RCTs merit study. Does the setting of ophthalmic education make a difference, for example whether hospital based or in the community? Is ophthalmology better taught early on or later in a medical course? In medicine is a stand-alone ophthalmology module more effective 
than ophthalmology teaching integrated throughout the course? Is there a role in ophthalmology for interprofessional learning? If these and other questions are addressed by RCTs, ethical committees, journal reviewers and editors have a responsibility to insist on rigorous methods. As a guide for conducting and reporting RCTs in an educational context, the CONSORT guidelines offer a useful starting point, but further discussion may be needed in the educational community about whether and how to adapt these guidelines for the field.

\section{CONCLUSIONS.}

RCTs have several limitations as means to gather evidence on medical education. However all methods of acquiring of new knowledge have both value and limitations. Ophthalmologists regarding or entering the pedagogical arena should not be blind to the merits of non-RCT based data.

ACKNOWLEDGEMENTS: none

COMPETING INTERESTS: none

FUNDING: none sought or granted

ETHICAL APPROVAL: not required for this study

\section{REFERENCES}

1. Succar T, Grigg J, Beaver HA, Lee AG. A systematic review of best practices in teaching ophthalmology to medical students. Survey of 
ophthalmology 2016;61(1):83-94 doi:

10.1016/j.survophthal.2015.09.001[published Online First: Epub Date]|.

2. Gupta RR, Lam WC. Medical students' self-confidence in performing direct ophthalmoscopy in clinical training. Canadian journal of ophthalmology. Journal canadien d'ophtalmologie 2006;41(2):169-74 doi: 10.1139/I06004[published Online First: Epub Date]|.

3. Eze BI, Oguego NC, Uche JN, Shiwoebi JO, Mba CN. Assessing the knowledge and skills in clinical ophthalmology of medical interns: survey results from enugu, South-eastern Nigeria. Middle East African journal of ophthalmology 2012;19(1):135-40 doi: 10.4103/09749233.92130[published Online First: Epub Date]|.

4. Featherstone PI, James C, Hall MS, Williams A. General practitioners' confidence in diagnosing and managing eye conditions: a survey in south Devon. The British journal of general practice : the journal of the Royal College of General Practitioners 1992;42(354):21-4

5. Jacobs DS. Teaching doctors about the eye: trends in the education of medical students and primary care residents. Survey of ophthalmology 1998;42(4):383-9

6. The Consolidated Standards of Reporting Trials 2010 checklist. Secondary The Consolidated Standards of Reporting Trials 2010 checklist. http://www.consort-statement.org.

7. Harden RM, Grant J, Buckley G, Hart IR. BEME Guide No. 1: Best evidence medical education. Medical teacher 1999;21(6):553-62

8. van der Vleuten CP, Driessen EW. What would happen to education if we take education evidence seriously? Perspectives on medical education 2014;3(3):222-32 doi: 10.1007/s40037-014-0129-9[published Online First: Epub Date]|.

9. Torgerson $\mathrm{CJ}$. Educational research and randomised trials. Medical education 2002;36(11):1002-3

10. Todres $M$, Stephenson A, Jones R. Medical education research remains the poor relation. Bmj 2007;335(7615):333-5 doi: 10.1136/bmj.39253.544688.94[published Online First: Epub Date]|.

11. Tso MO, Goldberg MF, Lee AG, Selvarajah S, Parrish RK, 2nd, Zagorski Z. An international strategic plan to preserve and restore vision: four 
curricula of ophthalmic education. American journal of ophthalmology 2007;143(5):859-65 doi: 10.1016/j.ajo.2007.01.055[published Online First: Epub Date]|.

12. Purbrick RM, Chong NV. Direct ophthalmoscopy should be taught to undergraduate medical students--No. Eye 2015;29(8):990-1 doi: 10.1038/eye.2015.91[published Online First: Epub Date]|.

13. International Task Force on Opthalmic Education of Medical S, International Council of $\mathrm{O}$. Principles and guidelines of a curriculum for ophthalmic education of medical students. Klinische Monatsblatter fur Augenheilkunde 2006;223 Suppl 5:S1-19 doi: 10.1055/s-2006951844[published Online First: Epub Date]|.

14. Hedges L OI. Statistical Methods for Meta-Analysis. New York: Academic Press, 1985.

15. Regehr G. It's NOT rocket science: rethinking our metaphors for research in health professions education. Medical education 2010;44(1):31-9 doi: 10.1111/j.1365-2923.2009.03418.x[published Online First: Epub Date]|.

16. Dornan T, Peile E, Spencer J. On 'evidence'. Medical education 2008;42(3):232-4 doi: 10.1111/j.1365-2923.2007.02997.x[published Online First: Epub Date]|.

17. Sullivan GM. Getting off the "gold standard": randomized controlled trials and education research. Journal of graduate medical education 2011;3(3):285-9 doi: 10.4300/JGME-D-11-00147.1[published Online First: Epub Date]|.

18. Norman G. RCT = results confounded and trivial: the perils of grand educational experiments. Medical education 2003;37(7):582-4

19. Belfield C, Thomas H, Bullock A, Eynon R, Wall D. Measuring effectiveness for best evidence medical education: a discussion. Medical teacher 2001;23(2):164-70 doi:

10.1080/0142150020031084[published Online First: Epub Date]|. 20. McGaghie WC. Medical education research as translational science. Sci Transl Med 2010;2(19):19cm8 doi: 10.1126/scitransImed.3000679[published Online First: Epub Date]|. 
21. Zendejas B, Brydges R, Wang AT, Cook DA. Patient outcomes in simulation-based medical education: a systematic review. J Gen Intern Med 2013;28(8):1078-89 doi: 10.1007/s11606-012-2264-5[published Online First: Epub Date]|.

22. Succar T, Zebington G, Billson F, et al. The impact of the Virtual Ophthalmology Clinic on medical students' learning: a randomised controlled trial. Eye (Lond) 2013;27(10):1151-7 doi: 10.1038/eye.2013.143[published Online First: Epub Date]|. 